\title{
Infection prevention and control measures for acute respiratory infections in healthcare settings: an update
}

W.H. Seto, ${ }^{1}$ J.M. Conly, ${ }^{2}$ C.L. Pessoa-Silva, ${ }^{3}$ M. Malik ${ }^{4}$ and S. Eremin ${ }^{3}$

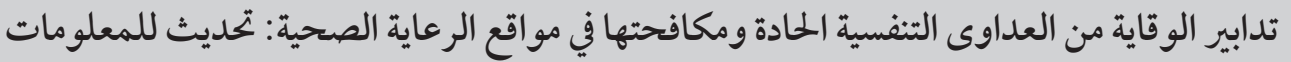

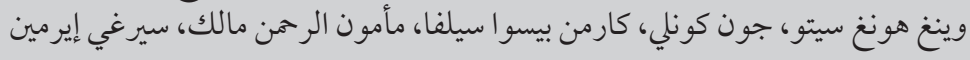

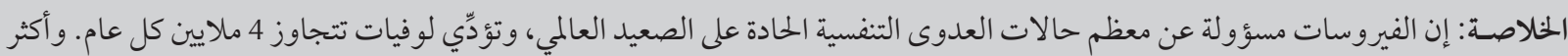

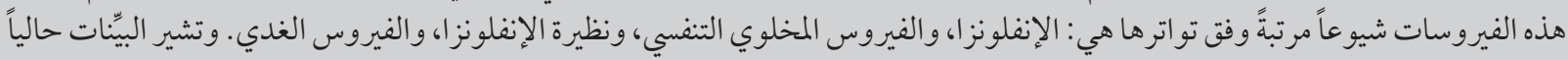

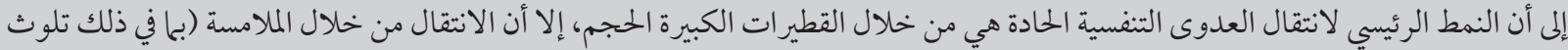

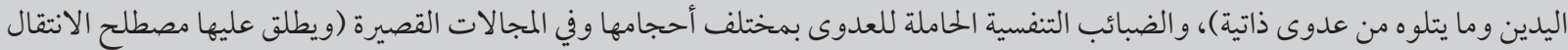

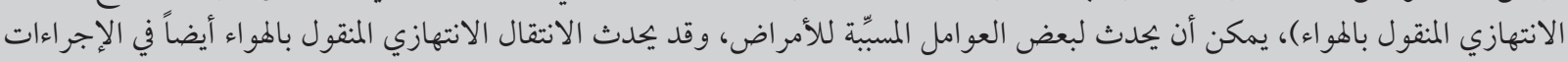

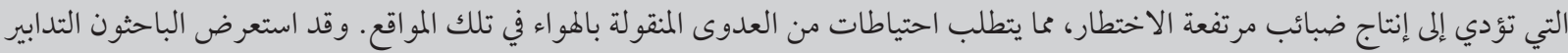

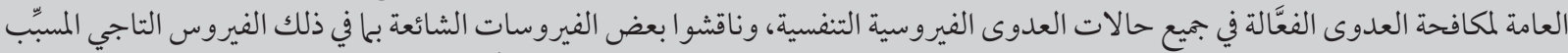

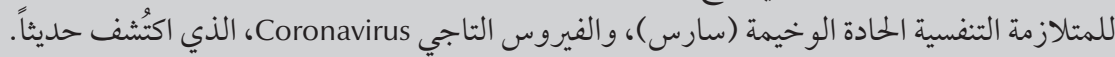

ABSTRACT Viruses account for the majority of the acute respiratory tract infections (ARIs) globally with a mortality exceeding 4 million deaths per year. The most commonly encountered viruses, in order of frequency, include influenza, respiratory syncytial virus, parainfluenza and adenovirus. Current evidence suggests that the major mode of transmission of ARIs is through large droplets, but transmission through contact (including hand contamination with subsequent selfinoculation) and infectious respiratory aerosols of various sizes and at short range (coined as "opportunistic" airborne transmission) may also occur for some pathogens. Opportunistic airborne transmission may occur when conducting highrisk aerosol generating procedures and airborne precautions will be required in this setting. General infection control measures effective for all respiratory viral infections are reviewed and followed by discussion on some of the common viruses, including severe acute respiratory syndrome (SARS) coronavirus and the recently discovered novel coronavirus.

Prévention des infections et mesures de lutte contre les infections respiratoires aiguës en milieu de soins : le point sur la situation

RÉSUMÉ Les virus sont responsables de la majorité des infections des voies respiratoires aiguës dans le monde avec une mortalité supérieure à quatre millions de décès par an. Les virus les plus fréquents sont, par ordre décroissant, celui de la grippe, le virus respiratoire syncytial, le virus paragrippal et l'adénovirus. Les données actuellement disponibles laissent penser que les grosses gouttelettes constituent le principal mode de transmission des infections des voies respiratoires aiguës, mais que la transmission par le contact (notamment la contamination par les mains suivie par une auto-inoculation) et par des aérosols respiratoires infectieux de différentes tailles et de courte portée (appelées transmissions par voie aérienne « opportunistes ») peut aussi se produire pour certains agents pathogènes. Une transmission par voie aérienne opportuniste peut survenir lors de l'utilisation de procédures générant des aérosols impliquant un risque élevé. Dans ce cas, des précautions contre une transmission aérienne sont requises. Des mesures de lutte anti-infectieuses générales efficaces contre toutes les infections respiratoires virales font l'objet d'un examen puis de discussions concernant certains virus courants, notamment le coronavirus du syndrome respiratoire aigu sévère et le nouveau coronavirus découvert récemment.

${ }^{7}$ Department of Community Medicine, School of Public Health, University of Hong Kong, Hong Kong, People's Republic of China. ${ }^{2}$ Departments of Medicine, Microbiology, Immunology and Infectious Diseases, Calvin, Phoebe and Joan Synder Institute for Chronic Diseases, Faculty of Medicine, University of Calgary, Calgary, Canada.

${ }^{3}$ Department of Pandemic and Epidemic Diseases, World Health Organization, Geneva, Switzerland (Correspondence to S. Eremin: eremins@who.int). ${ }^{4}$ Department of Communicable Disease Prevention and Control, World Health Organization Regional Office for the Eastern Mediterranean, Cairo, Egypt. 


\section{Introduction}

Acute respiratory infections (ARIs) cause widespread diseases globally and are responsible for over 4 million deaths each year [1]. The incidence of ARIs is especially high among infants, children, and the elderly and is more pronounced in low- and middle-income countries $[1,2]$. ARIs may affect either or both the upper or lower respiratory tract and infections involving the lower respiratory tract may be especially severe. Although bacteria are significant pathogens, the most common etiologies of ARIs are viral and they are frequent causes of hospital admissions and nosocomial outbreaks. Determining the magnitude of the extent of disease due to ARIs has been difficult because of the lack of laboratory diagnostic capabilities, but in recent years many hospital laboratories have established rapid viral diagnostic capabilities. In Hong Kong, for example, the capacity for both rapid diagnosis and viral culture has existed for the public sector since 1995, covering $90 \%$ of hospital beds in the territory. Laboratory data from Hong Kong identified influenza $A$ and influenza $B$ as accounting for about $50 \%$ of the patients diagnosed with viral respiratory infections, followed by respiratory syncytial virus (RSV) at about $20 \%$, and parainfluenza and adenovirus at about $15 \%$ each. Rhinovirus accounts for about 3\%, but this is probably an underestimate since specimens are less frequently submitted for these cases, which generally have mild symptoms [3].

The practice of infection control for patients with ARIs has its own particular challenges. The present review focuses mainly on infection prevention and control measures that are considered effective in healthcare settings, and discusses the relevance of these measures during health care for probable or confirmed case of novel coronavirus infections. Of special pertinence are 4 related systematic reviews recently commissioned by the World Health Organization [4-7] and a World
Health Organization guideline released on this subject [8] which covers infection control recommendations on key issues which are summarized later in this article.

\section{General infection control measures for ARIs in healthcare settings}

To develop effective strategies for infection control, it is critical to first understand the mode of transmission of these viruses. As these pathogens infect the respiratory tract and the virus can be disseminated into the air by coughing, it had been assumed in the past that the airborne route of transmission was important. Research over the years has provided evidence that this is not the case. Though knowledge of transmission modes continues to evolve, current evidence indicates that the major mode of transmission of most ARIs is through large droplets, but transmission through contact (including hand contamination with subsequent self-inoculation) and infectious respiratory aerosols of various sizes and at short range may also occur for some pathogens [9]. In an infected individual, a cough would generally produce large droplets, in the order of $10 \mu \mathrm{m}$ in diameter or larger, and these large droplets would generally fall to ground within 1 metre of the patient [10]. This distance of 1 metre for viral droplets was first identified for RSV in a study by Hall and Douglas [11]. Large droplets of this size, because of their weight and size, generally cannot remain suspended in the air [9]. Consequently, infection control precautions will only be necessary when the healthcare worker comes within 1 metre of the patient. This is the rationale behind the recommendations under "droplet precautions", which will be discussed below.
Some respiratory viruses, notably RSV, parainfluenza, and adenovirus, may be emitted in large quantities in respiratory secretions. With extensive contamination of the patient's environment, contact transmission can occur. Contact transmission refers to transfer of viruses and other microbes resulting from direct physical contact between infectious secretions from an infected or colonized person or via hands, environmental surfaces or inanimate objects which are contaminated by infectious secretions [9]. The isolation measure for these settings is designated "contact precautions", which will also be discussed below. In these settings with viruses associated with large droplet and contact transmission (including metapneumovirus [12] because of its similarity to RSV) a patient generally will not cough out droplet nuclei of $<5$ $\mu$ and therefore infectious material will not be disseminated for long distances through the air. Thus "airborne precautions" are generally not necessary. At present, none of these acute respiratory viral pathogens is classified as airborne [13]. However it should be noted that those respiratory viruses typically associated with large droplet and contact transmission may spread by the airborne route under special circumstances. Thus modes of transmission are not mutually exclusive and there may be settings or circumstances where transitions between modes of transmission may occur. This mode of transmission is described as "opportunistic airborne transmission" by Roy and Milton [14], who also stressed that such infections would not require "airborne infection isolation". Rather, one should be alert to settings and circumstances where this "opportunistic airborne transmission" may occur, such as with aerosol generating procedures.

Airborne or aerosol transmission refers to dissemination of microorganisms by aerosolization, and occurs when microorganisms are contained in droplet nuclei of a size $<5-10 \mu \mathrm{m}$, that result 
from evaporation of large droplets or in dust particles that remain suspended in the air [9]. Airborne transmission may occur over long distances ( $>1$ metre) and the microorganisms usually settle in the lower respiratory tract [14].

\section{Administrative \\ controls and measures for early recognition and isolation}

Infection control measures can only be effectively implemented in healthcare facilities when administrative controls are in place; this includes including establishing sustainable infrastructure and activities to maintain infection control practices, clear policies on early recognition of ARIs of potential concern, and access to prompt laboratory testing for identification of the etiologic agents. The healthcare facilities should also have adequate patient-to-staff ratios, provide adequate staff training, and establish appropriate staff vaccination and prophylaxis programmes [8].

Given the ongoing spread of viral respiratory infections globally, the World Health Organization (WHO) released a guideline in 2007 entitled Infection prevention and control of epidemic- and pandemic-prone acute respiratory infections in health care [8]. It will be referred to as the "ARI guideline" in subsequent discussion. This guideline recommends that in all hospitals, administrative measures should be taken to set up a system for patients with ARI so that they are managed in a coordinated manner with timely reporting to the public health authorities. The decision tree algorithm is shown in Figure 1 [8].

When a patient is first seen in the hospital or other healthcare site, usually in an outpatient setting, a system should be established for clinical triage where patients are screened for specific signs and symptoms of ARI. The moment these symptoms are detected, the infection control measures shown in the upper box of Figure 1 should be implemented. They are basically general infection control measures but include accommodating patients at least 1 metre away from other patients.

Both epidemiological and clinical clues should be obtained from patients. The emergence of severe, novel viral respiratory infections of public health concern such as a new pandemic influenza strain should prompt an appropriate travel and occupational history. A contact history with any known case or cluster of ARIs of public health concern should be elucidated. Clinical clues, such as the patient having severe respiratory illness after exposure to a cluster of ARI of unknown etiology but with a high mortality rate, may also be important. If these clues suggest that the patient has an ARI of public health concern, he/she should be isolated in a single, well-ventilated room if possible. However if it is a new virus, and the mode of transmission is still unclear, an airborne precaution room is recommended. The details surrounding the case may also be reported to the public health authorities depending on local policies. Relevant specimens should be submitted to the laboratory and once a specific etiologic diagnosis is made (Figure 1), the specific infection control measures, as recommended in the guidelines or in Table 1, should be followed.

\section{General measures within healthcare settings}

Surveillance is extremely useful so that hospitals are alerted to outbreaks circulating in the community and will be an aid to early diagnosis and isolation of patients. A system to alert infection control personnel, e.g when there are $\geq 3$ patients with influenza-like illnesses from a single ward, is also extremely useful. Immediate assessment of the possibility of an outbreak should be initiated, so that early isolation or discharge of patients can be undertaken [8].
Once admitted into the healthcare facility, the essential general infection control measures include rigorous hand hygiene, standard precautions and respiratory hygiene. Hand hygiene is extremely important and every hospital should implement the $\mathrm{WHO}$ hand hygiene guideline that has been introduced worldwide [15]. It has been demonstrated that alcohol hand rubs are effective against all the respiratory viruses. Standard precautions are the measures initially introduced for all patients to reduce the risk of blood-borne pathogens. It also covers respiratory viral infections and as part of standard precautions, healthcare workers must utilize surgical masks and eye protection when there is significant risk of contamination from patients with profuse acute respiratory symptoms. For the person with a cough, "respiratory hygiene" is a measure to contain respiratory secretions by providing them with tissues for covering the mouth and nose while coughing or providing surgical masks for the patients [13].

The 2 main isolation precautions for acute viral respiratory infections are droplet and contact precautions. It is important to stress that standard precautions and strict hand hygiene are integral parts of all of these precautions. The key element of droplet precautions is wearing a surgical mask whenever healthcare workers come within 1 metre of the patient; for contact precautions, it is wearing a gown and gloves on entering the patient's room and removing them on leaving [8]. Recent systematic reviews $[5,6]$ have shown the effectiveness of these measures.

"Quarantine" is an infection control measure recommended for some infectious diseases, but it should be noted that there is no such recommendation in any guidelines for the present list of acute viral respiratory infections [8]. Quarantine involves the segregation of healthy contacts and it was the policy for severe acute respiratory syndrome (SARS) in many countries. Such a drastic measure for SARS was carried out 
Patient

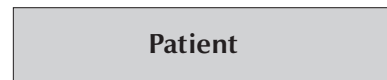

Infection control measures
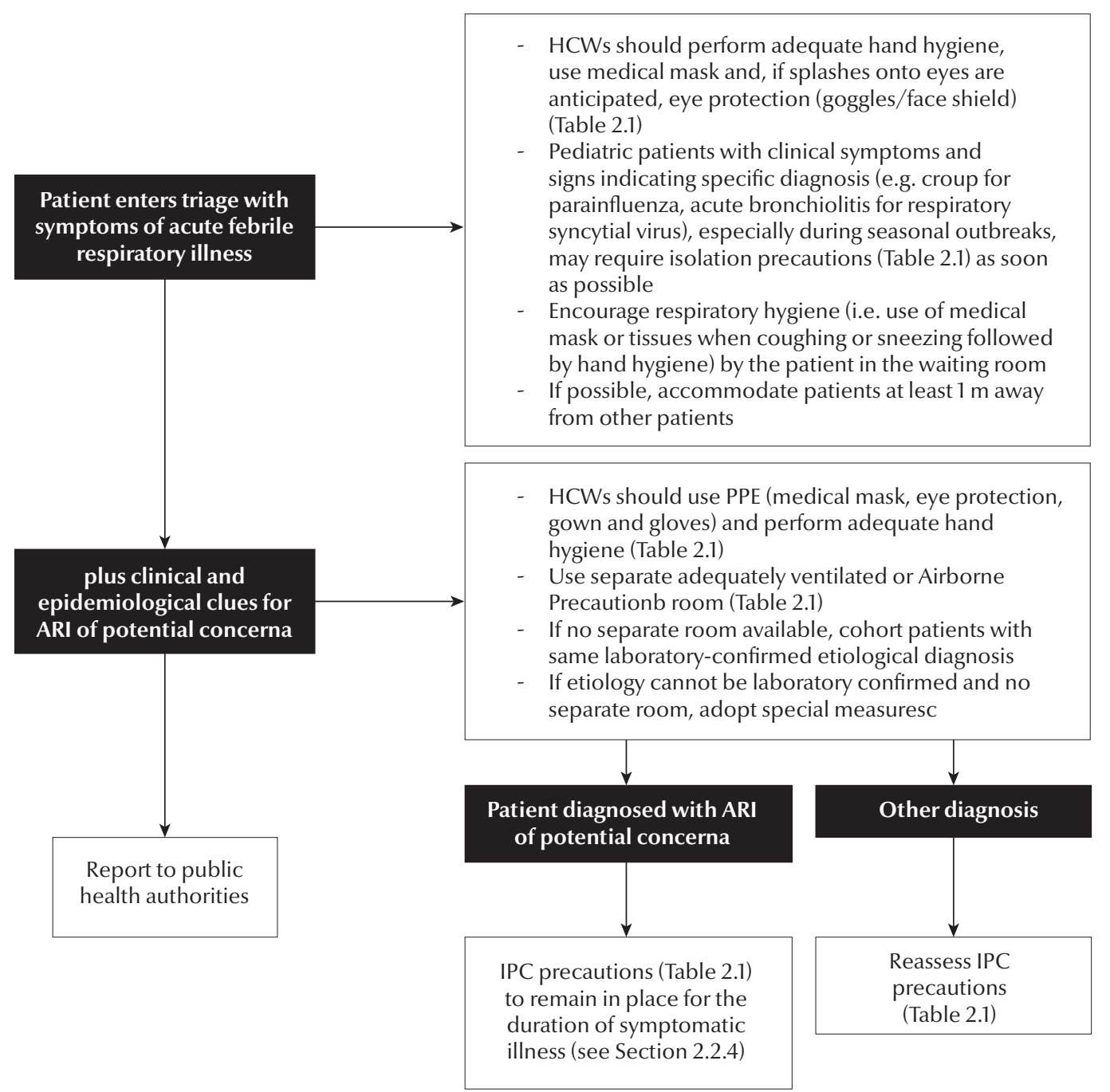

Figure 1 Decision-tree for infection prevention and control (IPC) measures for patients known or suspected to have an acute respiratory infection (ARI) [8] (PPE = personal protective equipment)

for the sake of caution, but the present evidence does not support the need for quarantine because subclinical infection is shown to be almost nonexistent [16] and even mildly symptomatic cases have not been reported [17].

Cohorting is the process of isolating patients with the same diagnosis in the same isolation room and since significant surges of these viral respiratory infections do occur, especially in the winter months, it often is needed. Many hospitals have the problem of admitting large numbers of patients with infectious respiratory syndromes, especially among paediatric patients, and where there is insufficient isolation capacity to place them in separate rooms before a specific viral diagnosis is available. A possible solution, suggested in the ARI guideline is to place all of these patients on droplet precautions in the same room but ensuring that all beds are at least 1 metre apart and having healthcare workers wear medical masks whenever they are within 1 metre of the patient [8]. There is no sharing of specific patient care equipment, such as stethoscopes, and patient medical records are not placed by the bedside but at the nursing station. Patients are advised not to leave their beds without permission, which is especially important for paediatric patients, and also the common play area found in most paediatric wards. When an etiologic diagnosis is established, infected patients are taken from this area and placed under the appropriate precautions as shown in Table 1. Such modified cohorting of respiratory illnesses has been reported to be successful in reducing nosocomial respiratory viral infections in paediatric units $[18,19]$. For adult wards, such measures may also be adapted with care, but when toilets are shared, it is important to ensure proper disinfection and adequate hand hygiene after use [8]. 


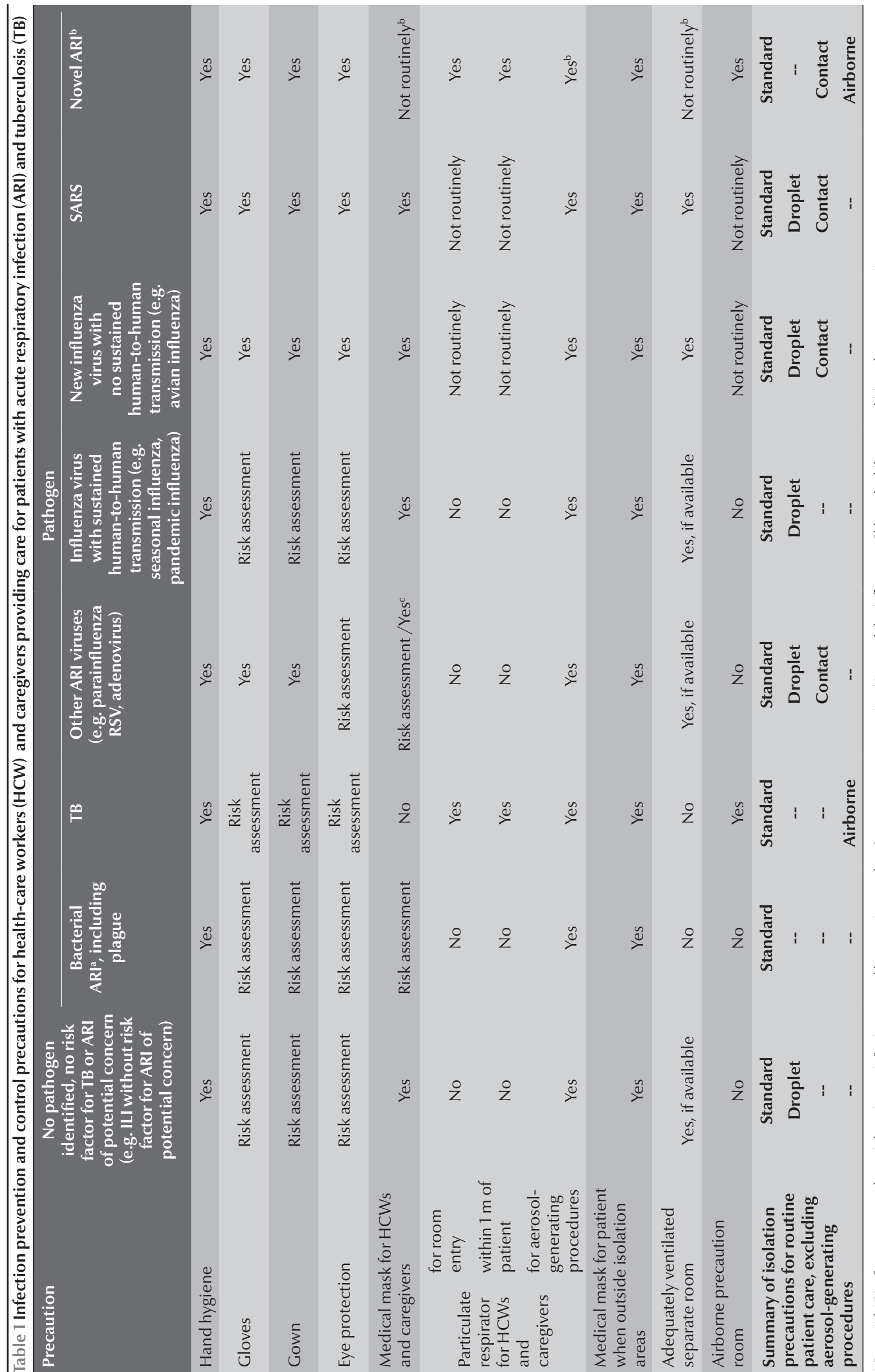

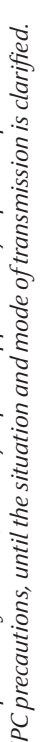
월 ह ฐ 过 है हิ 


\section{Aerosol generating procedures}

As mentioned previously, ARIs are generally not transmitted by air but aerosols of $<5 \mu$ may be generated in certain procedures labelled as "aerosol generating procedures" and transmitted at short distance. The risk of "opportunistic" airborne transmission will then be a real possibility, and airborne precautions will be required in these settings.

There is intense debate on the list of aerosol generating procedures that are associated with increased risk of infection transmission. Recently the Canadian Agency for Drugs and Technologies in Health completed a systematic review [4] which demonstrated that tracheal intubation was most consistently associated across multiple studies with an increased risk of SARS transmission to health-care workers, or was a risk factor for transmission of SARS. Four cohort studies revealed a pooled odds ratio [OR] of 6.6 [95\% confidence interval (CI): 2.3-18.9], and 4 case-control studies revealed a pooled OR of 6.6 (95\% CI: 4.1-10.6), which were remarkably consistent. No other procedures emerged with such a clear association. There were 2 studies reported for non-invasive ventilation which demonstrated a pooled OR of 3.1, but they were low quality studies in which the association in one was not statistically significant [20] and the other was also not significant after multivariate analysis [21]. On the basis of the review, the WHO has made a strong recommendation in the recently revised ARI guideline that identifies intubation for special attention as a procedure associated with risk of transmission of respiratory viruses [8] (see recommendations 6 and 7 in Table 2).

\section{Recommendations for infection control in the WHO ARI guideline}

Based on the systematic reviews, the $\mathrm{WHO}$ has updated recommendations on 10 key issues in the recently revised ARI guideline, illustrated in Table 2 [8]. Synthesizing the evidence and formulating the recommendations was done using the GRADE (Grading of Recommendations Assessment, Development and Evaluation) framework according to the WHO Handbook for Guideline Development [22].

\section{Measures for specific viral infections}

The measures for specific viral infections that are commonly encountered are summarized in Table 1, adapted from the 2007 guideline [8]. Key issues for the various viral infections are discussed below.

\section{Influenza}

Controversy surrounds the mode of transmission of influenza, especially with an outbreak report suggesting that it could be airborne [23]. However, recent reviews suggest that the basic mode of transmission is still considered to be via droplets [24-26]. Currently, influenza as listed in the Centers for Disease Control and Prevention guidelines requires droplet precautions [13], and, similarly, the World Health Organization (WHO) recommends that standard precautions and droplet precautions suffice for caring for patients infected with influenza [8].

Annualvaccination with trivalent inactivated (the most common) vaccine is the primary means of prevention and control of seasonal influenza, and is one of the recommendations in Table 2. A systematic review has been conducted which supports the recommendation for vaccinating healthcare workers but the quality of evidence is actually low [7].

The WHO guideline recommends both standard and droplet precautions, which includes the use of a medical mask rather than a facial particulate respirator for the healthcare worker. Use of the particulate respirators is only recommended for aerosol generating procedures such as intubation [27].

A study published in 2012 demonstrated the effectiveness of the WHO pandemic infection control guideline. When the WHO guideline was adopted, there was no significant difference in the infection rate of clinical staff who were exposed to $\mathrm{pH} 1 \mathrm{~N} 1$ 2009-infected patients compared to non-clinical staff who do not see patients at all [28].

\section{Avian influenza}

There is now general consensus that the mode of transmission for avian influenza is via droplet, and studies have shown that human-to-human spread is possible but is a rare event [29] and sustained, efficient, human-to-human transmission has not been reported to date. The WHO recommends droplet and contact precautions in their ARI guideline [8] and the first community outbreak of avian influenza reported in Hong Kong in 1997 [30] was successfully controlled in hospital clusters using such precautions.

\section{Severe acute respiratory syndrome} (SARS) and coronavirus infections

When SARS was first reported, the emotional response was intense and widespread. This is understandable, because it was a new disease and more than 1700 healthcare workers were infected. Subsequently, studies conducted in Hong Kong and elsewhere clearly demonstrated that infection control measures are effective. A case-control study on staff providing direct patient care to 11 proven SARS patients was reported comparing the infection control precautions of the 241 non-infected staff with the 13 infected staff [31]. Four specific measures were expressly studied: (1) the washing of hands and the wearing of (2) masks, (3) gowns, and (4) gloves. The results showed that if proper droplet and contact precautions were undertaken by the staff, they would be protected [31].

Although standard infection control measures will prevent transmission of 
Table 2 Ten WHO recommendations for infection prevention and control (IPC) and of acute respiratory infections (ARIs)

Recommendations

Overall ranking

1. Use clinical triage for early identification of patients with ARIs to prevent the transmission of ARI Strong pathogens to HCWs and other patients.

2. Respiratory hygiene (i.e. covering the mouth and nose during coughing or sneezing with a medical mask, tissue, or a sleeve or flexed elbow followed by hand hygiene) should be used in persons with ARIs to reduce the dispersal of respiratory secretions containing potentially infectious particles.

3. Maintain spatial separation (distance of at least $1 \mathrm{~m}$ ) between each ARI patient and others, including HCWs (without the use of PPE), to reduce the transmission of ARI.

4. Consider the use of patient cohorting (i.e. the placement of patients infected or colonized with the same laboratory-identified pathogens in the same designated unit, zone or ward). If cohorting is not possible apply special measures (i.e. the placement of patients with the same suspected diagnosis similar epidemiological and clinical information - in the same designated unit, zone or ward) within a health-care setting to reduce transmission of ARI pathogens to HCWs and other patients.

5. Use appropriate PPE as determined by risk assessment (according to the procedure and suspected pathogen). Appropriate PPE when providing care to patients presenting with ARI syndromes may include a combination of the following: medical mask (surgical or procedure mask), gloves, longsleeved gowns and eye protection (goggles or face shields).

6. Use PPE, including gloves, long-sleeved gowns, eye protection (goggles or face shields) and facial mask (surgical or procedure mask, or particulate respirators) during aerosol-generating procedures that have been consistently associated with an increased risk of transmission of ARI pathogens.1 The available evidence suggests that performing or being exposed to endotracheal intubation either by itself or combined with other procedures (e.g. cardiopulmonary resuscitation or bronchoscopy) is consistently associated with increased risk of transmission.

7. Use adequately ventilated single rooms when performing aerosol-generating procedures that have been consistently associated with increased risk of ARI transmission.

8. Vaccinate HCWs caring for patients at high risk of severe or complicated influenza disease, to reduce illness and mortality among these patients.

Strong

Strong

Conditional

Considerations for Ultraviolet Germicidal Irradiation - no recommendations possible.

10. Implement additional IPC precautions at the time of admission and continue for the duration of symptomatic illness, and modify according to the pathogen and patient information. Always use Standard Precautions. There is no evidence to support the routine application of laboratory tests to determine the duration of IPC precautions.

When a novel ARI is identified and the mode of transmission is unknown, it may be prudent to implement the highest level of IPC precautions whenever possible including the use of fit tested particulate respirators, until the mode of transmission is clarified.

Patient information (e.g. age, immune status and medication) should be considered in situations where there is concern that a patient may be infectious for a prolonged period. $H C W=$ health-care workers; $P P E=$ personal protective equipment

the SARS coronavirus (SARS-CoV), the correct practices must be inculcated in a properly organized programme for the entire hospital. The importance of leadership, intensive surveillance, and intense education of healthcare workers with adequate logistics cannot be overemphasized [32,33].

There was controversy in the literature regarding the transmission of SARS-CoV as to whether it was airborne, but this issue was addressed by Seto and Tang [34]. The outbreak in the Amoy Garden in Hong Kong published by $\mathrm{Yu}$ et al. used computerized fluid dynamic modelling and suggested that SARS-CoV could be transmitted by the airborne route [35]. It was an elegant study but it was a simulation, and presents a level of evidence not comparable to actual epidemiological comparative studies involving real patients with concomitant controls. The authors correctly point out in their conclusions that their study only "supports the probability of an airborne spread of SARS in the outbreak in Amoy Gardens." In an editorial regarding the article by Yu et al., Roy and Milton stated that "Hydraulic aerosol experiments combined with aerosol and epidemiologic modelling clearly implicated airborne transmission within the apartment complex" [14]. However, this "should not be considered to represent evidence that airborne infections necessarily cause explosive outbreaks" [14].
There are now reports supporting this contention, and that the use of medical masks when working within 1 metre of the patient is effective in preventing the transmission of SARS $[36,37]$.

\section{Infection prevention and control recommendations}

The emergence of a novel strain of coronavirus in September 2012 raised a global health alert as this novel virus belonged to the same family Coronaviridae as the SARS-CoV was [38]. There is now clear evidence [39] of limited, not 
sustained, human-to-human transmission, possibly involving different routes of transmission such as droplet and contact transmission, but the information on transmission and other features of the novel coronavirus ( $\mathrm{nCoV}$ ) is based on a small number of cases reported globally so far. Further studies are required to understand better the transmission dynamics associated with this $\mathrm{nCoV}$ infection.

Based on currently available information, however, it does not seem rational to change the current recommendations on infection, prevention and control (IPC) measures which have proven to be effective for SARS and other coronaviruses. The successful prevention of further amplification of $\mathrm{nCoV}$ infections associated with health care will depend on the maturity of IPC programmes and the implementation of administrative and engineering and environmental controls. Droplets and contact precautions and eye protection should be added to standard precautions for health-care workers or visitors in close contact when caring for patients with probable or confirmed nCoV infection in healthcare settings. Additional precautions should also be applied when performing aerosol-generating procedures that are thought to be associated with an increased risk of infection transmission. The experience with SARS-CoV has clearly shown that it is crucial that health-care workers are provided with the appropriate protection for caring for $\mathrm{nCoV}$-infected patients and followed up if exposure has occurred. The detailed IPC recommendations are available in the ARI guideline and on the WHO Coronavirus web page $[8,40]$.

The current scientific knowledge on the duration of infectivity of $\mathrm{nCoV}$ infection is limited. Based on currently available information, the isolation precautions need to be applied consistently during the duration of symptomatic illness and continued for not less than 24 hours after the resolution of symptoms. Until the epidemiology of the $\mathrm{nCoV}$ is better understood, and also considering other factors, testing for viral shedding could assist in decision-making, when available. On the other hand, a positive result for viral shedding does not necessarily imply effective infection transmission, and the epidemiological studies are the cornerstone for better informed decision making. Patient information (e.g. age, immune status and medication) should also be considered in situations where there is concern that a patient may be shedding the virus for a prolonged period. In such situations a more cautious approach, such as a longer duration of IPC precautions, maybe necessary

\section{References}

1. The world health report 2004: changing history. Geneva, World Health Organization, 2004 (http://www.who.int/whr/2004/ en/, accessed 7 May 2013).

2. Nair $\mathrm{H}$ et al. Global burden of respiratory infections due to seasonal influenza in young children: a systematic review and meta-analysis. Lancet, 2011, 378:1917-1930.

3. Seto W, Ho J. Healthcare-associated respiratory viral infections. In: Jarvis W, ed. Bennett and Brachman's hospital infections, 6th ed. (In press).

4. Tran $\mathrm{K}$ et al. Aerosol generating procedures and risk of transmission of acute respiratory infections to healthcare workers: a systematic review. PLoS ONE, 2012, 7:e35797.

5. Jefferson T et al. Physical interventions to interrupt or reduce the spread of respiratory viruses: systematic review. BMJ, 2008, 336:77.

6. Lee $\mathrm{K}$ et al. Physical interventions to interrupt or reduce the spread of respiratory viruses - resource use implications: a systematic review. CADTH Technology Overviews, 2012, 2(3):e2302.

7. Dolan GP et al. Vaccination of health care workers to protect patients at increased risk for acute respiratory disease. Emerging Infectious Diseases, 2012, 18:1225-1234.

8. Infection prevention and control of epidemic-and pandemic-prone acute respiratory diseases in health care. Geneva, World Health Organization, Global Alert and Response, 2007 (WHO/CDS/EPR/2007.6) (http://www.who.int/csr/ resources/publications/swineflu/WHO_CD_EPR_2007_6/ en/index.html, accessed 7 May 2013).

9. Hall CB. The spread of influenza and other respiratory viruses: complexities and conjectures. Clinical infectious disease, 2007, 45(3):353-359.
10. Rabenau HF et al. Efficacy of various disinfectants against SARS coronavirus. Journal of Hospital Infection, 2005, 61:107-111.

11. Hall CB, Douglas RG Jr. Modes of transmission of respiratory syncytial virus. Journal of Pediatrics, 1981, 99:100-103.

12. Crowe JEJ Jr. Human metapneumovirus as a major cause of human respiratory tract disease. Pediatric Infectious Disease Journal, 2004, 23(Suppl.):S215-S221.

13. Siegel JD et al., and the Healthcare Infection Control Practices Advisory Committee. 2007 Guideline for isolation precautions: preventing transmission of infectious agents in healthcare settings. Atlanta, Georgia, Centers for Disease Control, 2007 (http://www.cdc.gov/hicpac/2007ip/2007isolationprecauti ons.html, accessed 7 May 2013).

14. Roy CJ, Milton DK. Airborne transmission of communicable infection-the elusive pathway. New England Journal of Medicine, 2004, 350:1710-1712.

15. WHO guidelines on hand hygiene in health care. Geneva, World Health Organization, 2009 (http://www.who.int/gpsc/5may/ tools/9789241597906/en/index.html, accessed 7 May 2013).

16. Leung GM et al. SARS-CoV antibody prevalence in all Hong Kong patient contacts. Emerging Infectious Diseases, 2004, 10:1653-1656.

17. Leung GM et al. The epidemiology of severe acute respiratory syndrome in the 2003 Hong Kong epidemic: an analysis of all 1755 patients. Annals of Internal Medicine, 2004, 141:662-673.

18. Karanfil LV et al. Reducing the rate of nosocomially transmitted respiratory syncytial virus. American Journal of Infection Control, 1999, 27:91-96.

19. Mlinarić-Galinović G, Varda-Brkić D. Nosocomial respiratory syncytial virus infections in children's wards. Diagnostic Microbiology and Infectious Disease, 2000, 37:237-246. 
20. Fowler RA et al. Transmission of severe acute respiratory syndrome during intubation and mechanical ventilation. American Journal of Respiratory and Critical Care Medicine, 2004, 169:1198-1202.

21. Raboud J et al. Risk factors for SARS transmission from patients requiring intubation: a multicentre investigation in Toronto, Canada. PLoS ONE, 2010, 5:e10717.

22. WHO Handbook for Guideline Development. Geneva, World Health Organization, 2010 (http://www.who.int/hiv/topics/ mtct/grc_handbook_mar2010_1.pdf, accessed 7 May 2013.

23. Moser MR et al. An outbreak of influenza aboard a commercial airliner. American Journal of Epidemiology, 1979, 110:1-6.

24. Salgado CD et al. Influenza in the acute hospital setting. Lancet Infectious Diseases, 2002, 2:145-155.

25. Bridges CB, Kuehnert MJ, Hall CB. Transmission of influenza: implications for control in health care settings. Clinical infectious diseases, 37(8):1094-1101.

26. Stott DJ, Kerr G, Carman WF. Nosocomial transmission of influenza. Occupational Medicine (Oxford, England), 2002, 52:249-253.

27. Human infection with pandemic (H1N1) 2009 virus: updated interim WHO guidance on global surveillance. Geneva, World Health Organization, 2009 (http://www.who.int/csr/disease/ swineflu/WHO_case_definition_swine_flu_2009_04_29.pdf, accessed 7 May 2013).

28. Seto $\mathrm{WH}$ et al. Clinical and nonclinical health care workers faced a similar risk of acquiring 2009 pandemic H1N1 infection. Clinical infectious diseases, 2011, 53(3):280-283.

29. Buxton Bridges $\mathrm{C}$ et al. Risk of influenza A (H5N1) infection among health care workers exposed to patients with influenza A (H5N1), Hong Kong. Journal of Infectious Diseases, 2000, 181:344-348.

30. Yuen KY, Wong SS. Human infection by avian influenza A H5N1. Hong Kong Medical Journal, 2005, 11(3):189-199.
31. Seto WH et al.; Advisors of Expert SARS group of Hospital Authority. Effectiveness of precautions against droplets and contact in prevention of nosocomial transmission of severe acute respiratory syndrome (SARS). Lancet, 2003, 361:1519-1520.

32. Seto WH, Ching PTY, Ho PL. Infection control for SARS: evidence for efficacy of good practice and description of a successful model. In: Perris M, ed. Severe acute respiratory syndrome. Oxford, England, Blackwell Publishing, 2005:176-183.

33. Ho PL, Tang XP, Seto WH; HO. SARS: hospital infection control and admission strategies. Respirology (Carlton, Vic.), 2003, 8(Suppl.):S41-S45.

34. Tong TR, Tsang D. SARS infection control. Lancet, 2003, 362:76-77, author reply 76-77.

35. Yu ITS et al. Evidence of airborne transmission of the severe acute respiratory syndrome virus. New England Journal of Medicine, 2004, 350:1731-173.

36. Peck AJA et al.; SARS Pennsylvania Case Investigation Team. Lack of SARS transmission and U.S. SARS case-patient. Emerging Infectious Diseases, 2004, 10:217-224.

37. Park BJ et al. Lack of SARS transmission among healthcare workers, United States. Emerging Infectious Diseases, 2004, 10:244-248.

38. Malik M et al. Emergence of novel human coronavirus: public health implications in the Eastern Mediterranean Region. Eastern Mediterranean Health Journal, 2012, 18:1084-1085.

39. The Health Protection Agency (HPA), UK Novel Coronavirus Investigation Team. Evidence of person-to-person transmission within a family cluster of novel coronavirus infections, United Kingdom, February 2013. Eurosurveillance, 2013, 18(11):pii 2042 (http://www.eurosurveillance.org/images/ dynamic/EE/V18N11/art20427.pdf, accessed 7 May 2013).

40. Coronavirus infections. Geneva, World Health Organization, Global Alert and Response, 2013 (http://www.who.int/csr/ disease/coronavirus_infections/en/index.html, accessed 7 May 2013). 